\title{
Prognostic and therapeutic value of mitochondrial serine hydroxyl-methyltransferase 2 as a breast cancer biomarker
}

\author{
LAHONG ZHANG $^{1}$, ZHAOJUN CHEN $^{1},{\mathrm{DAN} X \mathrm{XE}^{2}}^{2}, \mathrm{QI} \mathrm{ZHANG}^{3}, \mathrm{XIYONG} \mathrm{LIU}^{4,5}$, \\ FRANK LUH ${ }^{5,6}$, LIQUAN HONG ${ }^{1}$, HANG ZHANG $^{7}$, FENG PAN $^{1}$, YUHUA LIU $^{1}$, \\ PEIGUO $\mathrm{CHU}^{8}$, SHU ZHENG ${ }^{6}$, GUOQIANG LOU ${ }^{1}$ and YUN YEN $^{9}$ \\ ${ }^{1}$ Department of Laboratory Medicine, Affiliated Hospital of Hangzhou Normal University, Hangzhou, Zhejiang 310015; \\ ${ }^{2}$ Department of Plastic Surgery, Second Affiliated Hospital of Zhejiang University, Hangzhou, Zhejiang 310009; \\ ${ }^{3}$ Hangzhou Hope Biotechnology Inc., Hangzhou, Zhejiang 310015, P.R. China; ${ }^{4}$ Biomarker Development, \\ California Cancer Institute, Temple City, CA 91780, USA; ${ }^{5}$ Taipei Medical University, School of Medicine, \\ Taipei 110, Taiwan, R.O.C.; ${ }^{6}$ Sino-American Cancer Foundation, Temple City, CA 91780, USA; \\ ${ }^{7}$ Cancer Institute, Zhejiang University, Hangzhou, Zhejiang 310009, P.R. China; \\ ${ }^{8}$ Department of Pathology, City of Hope National Medical Center, Duarte, CA 91010, USA; \\ ${ }^{9}$ Taipei Medical University, Taipei 110, Taiwan, R.O.C.
}

Received April 22, 2016; Accepted August 29, 2016

DOI: $10.3892 /$ or.2016.5112

\begin{abstract}
Mitochondrial serine hydroxylmethyltransferase 2 (SHMT2) is a key enzyme in the serine/glycine synthesis pathway. SHMT2 has been implicated as a critical component for tumor cell survival. The aim of the present study was to evaluate the prognostic value and efficiency of SHMT2 as a
\end{abstract}

Correspondence to: Dr Dan Xue, Department of Plastic Surgery, Second Affiliated Hospital of Zhejiang University, 88 Jiefang Road, Hangzhou, Zhejiang 310009, P.R. China

E-mail: xuedan@zju.edu.cn

Dr Guoqiang Lou, Department of Laboratory Medicine, Affiliated Hospital of Hangzhou Normal University, 126 Wenzhou Road, Hangzhou, Zhejiang 310015, P.R. China

E-mail: louguoqiang2015@163.com

Abbreviations: SHMT2, serine hydroxymethyltransferase 2 (mitochondrial); THF, tetrahydrofolate; ER, estrogen receptor; PR, progesterone receptor; MKI-67, marker of proliferation Ki-67; TNBC, triple-negative breast cancer, or basal-like breast cancer; HER2, human epidermal growth factor receptor 2; IHC, immunohistochemistry; GSEA, gene set enrichment analysis; OS, overall survival; PFS, progression-free survival; HR, proportional hazard ratio; 95\% CI, 95\% confidence interval; RRM2, human ribonucleotide reductase small subunit M2; IRM, immune response module; HDPP, HER2-derived prognostic predictor; pT stage, pathological tumor stage; $\mathrm{pN}$ stage, pathological lymph node stage

Key words: mitochondrial serine hydroxylmethyltransferase 2, ER-negative breast cancer, prognostic biomarker, gene set enrichment analysis biomarker in patients with breast cancer. Individual and pooled survival analyses were performed on five independent breast cancer microarray datasets. Gene signatures enriched by SHMT2 were also analyzed in these datasets. SHMT2 protein expression was detected using immunohistochemistry (IHC) assay in 128 breast cancer cases. Gene set enrichment analysis revealed that $S H M T 2$ was significantly associated with gene signatures of mitochondrial module, cancer invasion, metastasis and poor survival among breast cancer patients $(\mathrm{p}<0.05)$. The clinical relevance of SHMT2 was validated on IHC data. The mitochondrial localization of SHMT2 protein was visualized on IHC staining. Independent and pooled analysis confirmed that SHMT2 expression was associated with breast cancer tumor aggressiveness (TNM staging and Elson grade) in a dose-dependent manner $(\mathrm{p}<0.05)$. The prognostic performance of SHMT2 mRNA was comparable to other gene signatures and proved superior to TNM staging. Further analysis results indicated that SHMT2 had better prognostic value for estrogen receptor (ER)-negative breast cancer patients, compared to ER-positive patients. In cases involving stage IIb breast cancer, chemotherapy significantly extended survival time among patients with high SHMT2 expression. These results indicate that $S H M T 2$ may be a valuable prognostic biomarker in ER-negative breast cancer cases. Furthermore, SHMT2 may be a potential target for breast cancer treatment and drug discovery.

\section{Introduction}

Mitochondrial serine hydroxylmethyltransferase (SHMT) is a key enzyme in the serine/glycine pathway. This pathway involves the conversion of serine to glycine by catalyzing the transfer of a $\beta$-carbon from serine to tetrahydrofolate (THF) 
and generating 5,10-methylene-THF and glycine as byproducts. Two SHMT genes have been identified in the human genome, SHMT1 and SHMT2.SHMT1 encodes the cytoplasmic isozyme involved in de novo synthesis of thymidylate (1). In contrast, SHMT2 encodes the mitochondrial isozyme that participates in the synthesis of mitochondrial thymidine monophosphate (dTMP) $(1,2)$. SHMT1 and SHMT2 have important roles in human biochemical pathways, including the folate cycle, homocysteine metabolism and nuclear de novo thymidylate biosynthesis (3). Studies have shown that SHMT1 and SHMT2 expression is upregulated in cancer. Specifically, SHMT2 expression is significantly increased in cancers involving the breast, lung, ovary, prostate and skin (4-7). Moreover, elevated expression of SHMT2 has been found to be associated with poor prognosis in human cancers (8).

Worldwide, breast cancer remains a major cause of female deaths (9). Breast cancer can be broadly classified into four major molecular subtypes, depending on the specific genetic profile (i.e., luminal A, luminal B, triple-negative/basal-like and HER2 status) $(10,11)$. Each subtype has unique clinical, histopathological and prognostic characteristics (3). Luminal A and luminal B breast cancer have high expression of estrogen receptor $\left(\mathrm{ER}^{+}\right)$. HER2-positive and basal-like/triple-negative breast cancers (TNBCs) (12) are ER-negative (ER') and are associated with a poor prognosis (13). Recent studies suggest that the 5-year survival rate in patients with ER-negative breast cancer is $30 \%$, compared with a $90 \%$ survival rate for luminal A patients (14). The classification of molecular subtypes was used for therapeutic protocol selection and also for prediction of cancer metastases and post-relapse survival (15).

Numerous gene signatures have been developed to predict survival of breast cancer patients. Examples of these predictors include PI3K signature (16), 21-gene recurrence score (17) and core serum response signature (CSR) (18). The HER2-derived prognostic predictor (19) and 7-gene immune response module (20) have been proposed as means to identify patients with ER-negative breast cancer. However, these methods are costly and lack specific targets. Developing more accurate and economical gene signatures for therapeutic purposes may provide significant benefit to the medical community.

The objective of the present study was to evaluate the prognostic and therapeutic value of SHMT2 as a potential biomarker for breast cancer cases. We compared its performance with other currently available biomarkers and gene signatures. Five independent breast cancer microarray datasets were analyzed using individual and pooled approaches. We found that SHMT2 had a prognostic value in a specific subgroup of breast cancer patients. The prognostic power of SHMT2 mRNA was comparable to other gene signatures and biomarkers, most notably for patients in the ER-negative breast cancer subgroup. We also found that $S H M T 2$ had a potential predictive role in stage II breast cancer treatment.

\section{Materials and methods}

Breast cancer tissue samples. We used a retrospective population-based outcome strategy to analyze 128 breast cancer cases (ZJU set). All patients underwent modified radical mastectomy at Zhejiang University (ZJU) Hospital (Hangzhou, China) from January 2002 to December 2006.
The protocol for the use of human tissues was reviewed and approved by the Institutional Review Board (IRB). All patients provided written informed consent for the tissue samples to be used for scientific research. Patients who did not provide informed consent or who had multiple cancers were excluded from the study. The period of progression-free survival (PFS) was defined as the time from the date of the surgery to the date of tumor recurrence (local relapse or metastasis). Overall survival (OS) time was the time from the date of the surgery to the date the patient was last examined. Only breast cancer-related deaths were included as the end of the survival period. All ZJU set participants were followed up twice per year, until 30 September 2010. Pathoclinical and demographic data were collected by reviewing hospital records. The results for the characteristics of all 128 assessable breast cancer patients are presented in Table I.

Quantitative immunohistochemistry (IHC) assays. Hematoxylin and eosin staining results for all tissue blocks were reviewed by a pathologist. Then, the tissue samples were re-arranged and assembled into multiple tissue arrays (MTA). Each MTA was stored at room temperature. Protein levels of genes were stained in tissue sections from the MTAs, based on standardized deparaffinization and staining protocol $(21,22)$. For quality control, negative and positive samples were also included in each IHC staining set.

A commercially available anti-SHMT2 antibody (ab88664; Abcam) was used for the IHC procedure. SHMT2 specificity was confirmed using peptide blocking assay. The IHC condition for SHMT2 was optimized based on serial dilution results. Antibodies against ER (clone, SP1), PR (clone, PgR636), HER2 (clone, A0485) and Ki-67 (clone, MIB-1) were purchased from the Dako Company. The TP53 antibody (clone, DO-7) was purchased from the Vector Laboratories.

The cut-off values for ER, PR, HER2 and Ki-67 positivity were based on standard, published protocols $(23,24)$. Each sample was assigned to one of four intrinsic subtypes (i.e., luminal A, luminal B, HER2-positive and basal-like/TNBC, subtype), based on the IHC staining results (11). For the breast cancers, a CD $44^{+} / \mathrm{CD} 24 /$ low result indicated the presence of tumor stem/progenitor cells.

Double-blinding was performed to maintain quality control of IHC scoring and prevent observer and system bias. Two observers independently evaluated each IHC staining result. Discrepancies were peer reviewed by the two readers and an additional pathologist; missing samples were left blank. Most of the SHMT2 staining was visible in the cytoplasm and formed sand-like particles, but some heterogeneous staining was present in a few of the samples. SHMT2 is a mitochondrial protein. The immunoreactivity in the mitochondria was scored according to percentage and intensity of the staining. Stain intensity was scored as 0 (negative), 1 (weak), 2 (moderate) or 3 (strong). The morphologic pattern of IHC staining in each cell varied due to heterogeneity in cancer cells. In our scoring system, only specimens with at least $10 \%$ of the cells with positive staining were taken into consideration. The highest staining scores were tallied as the final score. Protein expression level consisted of four subgroups. These subgroups were negative (-), weakly positive (+), positive $(++)$ and strongly positive (+++) (Fig. 2A). In the Cox analysis, (-) and (+) were 
Table I. Demographic distribution of SHMT2 in breast cancer (ZJU set) patients.

\begin{tabular}{|c|c|c|c|}
\hline & \multicolumn{2}{|c|}{ SHMT2 } & \multirow[b]{2}{*}{ P-values ${ }^{b}$} \\
\hline & $\operatorname{High}(\%$ a $)$ & Low $(\%)$ & \\
\hline Age (years) & & & 0.5442 \\
\hline$<50$ & $49(76.6)$ & $15(23.4)$ & \\
\hline$\geq 50$ & $46(71.9)$ & $18(28.1)$ & \\
\hline Histological type & & & 0.0582 \\
\hline Ductal carcinoma & $79(78.2)$ & $22(21.8)$ & \\
\hline Lobular carcinoma & $9(50.0)$ & $5(50.0)$ & \\
\hline Other & $6(75.0)$ & $2(25.0)$ & \\
\hline pT stage ${ }^{c}$ & & & 0.0203 \\
\hline T0-1 & $21(60.0)$ & $14(40.0)$ & \\
\hline $\mathrm{T} 2-4$ & $71(80.1)$ & 17 (19.9) & \\
\hline pN stage ${ }^{c}$ & & & 0.0175 \\
\hline 0 & $39(63.9)$ & $22(36.1)$ & \\
\hline $1-3$ & $42(80.8)$ & $10(19.2)$ & \\
\hline$>3$ & $14(93.3)$ & $1(6.7)$ & \\
\hline Grade & & & 0.0067 \\
\hline 1, Well & $8(66.7)$ & $4(33.3)$ & \\
\hline 2, Mod & $27(60.0)$ & $18(40.0)$ & \\
\hline 3, Poor & $47(87.0)$ & $7(13.0)$ & \\
\hline ER & & & 0.3225 \\
\hline Negative & $36(78.3)$ & $10(21.7)$ & \\
\hline Positive & $44(69.8)$ & $19(30.2)$ & \\
\hline PR & & & 0.1004 \\
\hline Negative & $43(81.1)$ & $10(18.9)$ & \\
\hline Positive & $37(67.3)$ & $18(32.7)$ & \\
\hline HER2 & & & 0.2964 \\
\hline Negative & $66(73.3)$ & $24(26.7)$ & \\
\hline Positive & $20(75.4)$ & $4(24.6)$ & \\
\hline MKI67 & & & 0.0179 \\
\hline Negative & $26(61.0)$ & $16(39.0)$ & \\
\hline Positive & $56(82.3)$ & $12(17.7)$ & \\
\hline Molecular subtype & & & 0.5496 \\
\hline Luminal A & $20(75.0)$ & $12(25.0)$ & \\
\hline Luminal B/HER2- & $20(80.0)$ & $5(20.0)$ & \\
\hline Luminal B/HER2 ${ }^{+}$ & $6(75.0)$ & $2(25.0)$ & \\
\hline Basal-like TNBC & $15(83.3)$ & $3(16.7)$ & \\
\hline HER2-positive & $10(83.3)$ & $2(16.7)$ & \\
\hline CD44/CD24 status & & & 0.4380 \\
\hline $\mathrm{CD} 44^{+} / \mathrm{CD} 24^{-}$ & $37(71.1)$ & $15(28.9)$ & \\
\hline Other & $40(74.0)$ & $10(26.0)$ & \\
\hline
\end{tabular}

SHMT2, serine hydroxylmethyltransferase 2; ER, estrogen receptor; PR; progesterone receptor. There are 1, 5, 17, 9, 20, 14, 18, 29 and 1 missing cases in histological type, pT stage, grade, ER, PR, HER2, MKI67, molecular subtype and CD44/CD24 status. The classification of molecular types was based on ref. 11. a , \% represents positive rate of SHMT2_High equal to $\mathrm{N}_{\text {High }} /\left(\mathrm{N}_{\text {High }}+\mathrm{N}_{\text {Low }}\right) \times 100 \%$. ${ }^{\mathrm{b}}$ p-values were based on Pearson's Chi-square test. ${ }^{\mathrm{c}} \mathrm{pT}$ and $\mathrm{pN}$ stages are pathological tumor and lymph node stages. In pT stage, T0, T1, T2 and $\mathrm{T} 4$ represent tumor stage of breast cancer. In $\mathrm{pN}$ stage, the number represent how many lymph nodes are involved. grouped as SHMT2-low, and (++) and (+++) were grouped as SHMT2-high.

Public gene mRNA expression microarray datasets. Published data from human breast tissue gene expression array results are available from NIH/GEO or www.ebi.ac.uk/arrayexpress (4). Five independent breast cancer microarray datasets were chosen for the present study: Pawitan (GSE1456) (25), Ivshina (GSE4922) (26), Wang (GSE2034) (27), Desmedt (GSE7390) (28) and NKI (29) datasets (Table II). Detailed information concerning the downloaded datasets is presented in Table II. Three microarray SHMT2 fragments (214096_s_at, 214095_at and 214437_at) were used in Affymetrix U133 arrays. Since these three fragments yielded consistent results, we used the 214065_at signal to represent the expression levels of SHMT2 in the Pawitan, Ivshina, Wang and Desmedt microarray datasets (using Affymetrix chips). In the NKI set (using Agilent chip), one probe for $S H M T 2$ was found and was analyzed.

In the pooled analysis, we normalized the mRNA expression levels for the datasets. We re-stratified patients into four categories $\left(\mathrm{Q}_{1}, \mathrm{Q}_{2}, \mathrm{Q}_{3}\right.$ and $\left.\mathrm{Q}_{4}\right)$, based on the percentile of gene expression (Fig. 3, legend). Stratified SHMT2 expression level datasets were then pooled into a new dataset for further analysis.

Gene set enrichment analysis (GSEA). GSEA analysis software v2.0.14x (JAVA version) was downloaded from the Broad Institute Gene Set Enrichment Analysis website (www.broad.mit.edu/gsea). The standard protocol was based on previous published study protocols (30). The Pawitan set (159 cases) format was modified and converted into a GSEA dataset. The gene sets were downloaded from the Board Institute website/Molecular Signature Database (MSig DB). The number of permutations was set to 1,000 , and the phenotype label was based on SHMT2 (214065_at) expression levels. The ranked-list metric was generated and calculated using a Pearson model.

Data management and statistical methods. The worldwide gene expression database was downloaded, converted, constructed and managed using MS-Excel. The JMP 10.0 (SAS Institute Inc., Cary, NC, USA) application was used to perform the statistical analysis. Categorical variables were compared using $\chi^{2}$ analysis, Fisher's exact or the binomial tests of proportions. Kaplan-Meier analysis and Cox hazard proportional hazard models were used for outcome analysis. Data from patients with distant metastatic breast cancer that was not completely resected were excluded from the PFS analysis. Multivariate Cox analysis was used to adjust for covariate effects, and a stratified data analysis was used to reduce the effects of confounding on the estimated hazard ratios (HRs). Missing data were coded and excluded from the analysis.

\section{Results}

SHMT2 enriches cancer invasion-related gene signatures in breast cancers. To explore the clinical relevance and biological effects of $S H M T 2$, we performed a GSEA on a downloaded microarray dataset of 159 breast cancer cases 
Table II. Results of the overall review of the ZJU and worldwide microarray datasets.

\begin{tabular}{|c|c|c|c|c|c|c|}
\hline Dataset & ZJU & Ivshina & Wang & Pawitan & Desmedt & $\mathrm{NKI}^{\mathrm{b}}$ \\
\hline No. of patients & 223 & 249 & 286 & 159 & 198 & 295 \\
\hline Assessible cases ${ }^{\mathrm{a}}$ & 128 & 213 & 253 & 159 & 158 & 295 \\
\hline Date of study & 1999-2006 & 1987-1989 & 1980-1995 & 1994-1996 & 1980-1998 & 1984-1995 \\
\hline Microarray & N/A & $\begin{array}{c}\text { Affimetrix } \\
\text { HG-U133 }\end{array}$ & $\begin{array}{c}\text { Affimetrix } \\
\text { HG-U133 }\end{array}$ & $\begin{array}{l}\text { Affimetrix } \\
\text { HG-U133 }\end{array}$ & $\begin{array}{l}\text { Affimetrix } \\
\text { HG-U133 }\end{array}$ & $\begin{array}{c}\text { Agilent } \\
\text { 25K Chip }\end{array}$ \\
\hline Accession no. & N/A & GSE4922 & GSE2034 & GSE1456 & GSE7390 & N/A \\
\hline SHMT2 fragments & N/A & & & & & \\
\hline 214096_s_at & N/A & $\mathrm{Y}$ & $\mathrm{Y}$ & Y & $\mathrm{Y}$ & N/A \\
\hline 214095_at & N/A & $\mathrm{Y}$ & $\mathrm{Y}$ & $\mathrm{Y}$ & $\mathrm{Y}$ & N/A \\
\hline 214437_at & N/A & $\mathrm{Y}$ & $\mathrm{Y}$ & $\mathrm{Y}$ & $\mathrm{Y}$ & N/A \\
\hline Age at diagnosis & $\mathrm{Y}$ & $\mathrm{Y}$ & N/A & N/A & $\mathrm{Y}$ & $\mathrm{Y}$ \\
\hline Histological type & Y & N/A & N/A & N/A & $\mathrm{Y}$ & $\mathrm{Y}$ \\
\hline Elson grade & $\mathrm{Y}$ & $\mathrm{Y}$ & N/A & $\mathrm{Y}$ & $\mathrm{Y}$ & $\mathrm{Y}$ \\
\hline Tumor size & $\mathrm{Y}$ & $\mathrm{Y}$ & N/A & N/A & $\mathrm{Y}$ & $\mathrm{Y}$ \\
\hline Lymph node & $\mathrm{Y}$ & $\mathrm{Y}$ & $\mathrm{Y}$ & N/A & $\mathrm{Y}$ & $\mathrm{Y}$ \\
\hline Metastasis & $\mathrm{Y}$ & N/A & $\mathrm{Y}$ & N/A & $\mathrm{Y}$ & $\mathrm{Y}$ \\
\hline TNM stage & $\mathrm{Y}$ & $\mathrm{Y}$ & N/A & N/A & $\mathrm{Y}$ & $\mathrm{Y}$ \\
\hline ER status & $\mathrm{Y}$ & $\mathrm{Y}$ & $\mathrm{Y}$ & $\mathrm{Y}$ & $\mathrm{Y}$ & $\mathrm{Y}$ \\
\hline PR status & $\mathrm{Y}$ & N/A & N/A & N/A & N/A & $\mathrm{Y}$ \\
\hline HER2 status & $\mathrm{Y}$ & N/A & N/A & $\mathrm{Y}$ & N/A & $\mathrm{Y}$ \\
\hline MKI67 status & $\mathrm{Y}$ & N/A & N/A & N/A & N/A & $\mathrm{Y}$ \\
\hline P53 mutation & $\mathrm{Y}$ & $\mathrm{Y}$ & N/A & N/A & N/A & $\mathrm{N}$ \\
\hline Molecular subtype & $\mathrm{Y}$ & N/A & N/A & $\mathrm{Y}$ & N/A & $\mathrm{Y}$ \\
\hline Chemotherapy & $\mathrm{Y}$ & N/A & N/A & N/A & N/A & $\mathrm{Y}$ \\
\hline Radiotherapy & $\mathrm{Y}$ & N/A & N/A & N/A & N/A & $\mathrm{Y}$ \\
\hline Hormone therapy & $\mathrm{Y}$ & N/A & N/A & N/A & N/A & $\mathrm{Y}$ \\
\hline OS months ${ }^{\mathrm{c}}$ (range) & 8.9-104.9 & N/A & N/A & $2.2-101.9$ & 4.9-303.6 & $1.0-220.1$ \\
\hline PFS months ${ }^{\mathrm{d}}$ (range) & $2.5-104.9$ & $0-153.0$ & $2.0-171.0$ & $2.2-101.9$ & $4-231.4$ & $1.0-220.1$ \\
\hline
\end{tabular}

apatients without clinical information, follow-up data, or SHMT2 expression level were excluded from the present study. ${ }^{\mathrm{b} N K I}$ dataset used a 25,000-gene array (Agilent Technologies), which used the same fragments as Affymetrix HG-U133 array. ${ }^{\mathrm{c} O S}$, overall survival; ${ }^{\mathrm{P}} \mathrm{PFS}$, progression-free survival; N/A, not available; Y, yes; N, no; SHMT2, serine hydroxylmethyltransferase 2.

(GSE1456) and on other downloaded gene array datasets. Since the between-set results were similar, representative results from the Pawitan set analysis are presented. The results for the $S H M T 2$ enriched gene signatures are presented in Fig. 1A along with their statistical significance. Representative results are presented in Fig. 1B and C. The results revealed that SHMT2 was positively associated with at least two mitochondrial gene sets (Mootha and Wong gene modules). This finding reflected the compatibility and location of SHMT2 genes in the mitochondria. The overall GSEA results (Fig. 1A) revealed that SHMT2 was positively and significantly associated with metastasis, cancer invasion and poor survivability related gene sets. Taken together, these results suggested that high expression of SHMT2 may be associated with aggressiveness of breast cancer.

The expression of SHMT2 correlates with the aggressiveness of the breast cancer. The associations between SHMT2 protein expression levels and clinical characteristics of breast cancer were analyzed in the ZJU set. IHC staining of SHMT2 scoring are presented in Fig. 2A. The IHC staining results indicated that SHMT2 was primarily observed in the cytoplasm with mitochondrial location, and that some particle spread was present. To increase the study's statistical power, we have re-stratified subjects into SHMT2-low (- and +) and SHMT2-high (++ and +++) categories. The results of our statistical analysis indicated that increased SHMT2 protein levels were associated with larger tumor size $(\mathrm{p}=0.0203)$, positive lymph nodes $(\mathrm{p}=0.0175)$, poor differentiation $(\mathrm{p}=0.0067)$ and MKI67-positive results $(\mathrm{p}=0.0179)$ (Fig. 2B and Table I). The SHMT2 protein expression in various molecular subtypes of breast cancer varied, but not significantly. The results for the percentages of SHMT2-high varied in molecular subtypes. There were $75.0 \%$ for the luminal A cases, $80.0 \%$ for the luminal B/HER2(-) cases, $75.0 \%$ for the of luminal B/Her2(+) cases, $83.3 \%$ for the basal-like TNBC cases and $83.3 \%$ for 
A Pedersen_metastasis_by_ERBB2_isoform_6 Ramaswamy+metastasis DN Odonnel_metastasis_up Finefit_breast_cancers_kinome_blu Poola invassive breast cancer DN SMID_breast_cancer_luminal_A_UP Sotiriou breast cancer grade 1 vs 3 DN Turashvili breast_lobula carcinoma_vs_normal_UP SMID_breast_cancer_relapse_in_bone_UP Mootha_mitochondria

Wong mitochondria gene module Bidus metasitasis UP

Chandran_metastasis_top50_UP Grade metastasis_DN Liao_metastasis Provenzani metastasis_UP Ramaswamy metastasis UP Roessler_liver_cancer metastasis_UP Sung_metastasis_stroma_DN Winnepenninckx_melanoma metastasis_UP Zucchi_metastasis_UP Bertucci medullary vs ductal breast cancer_UP Farmer_breast_cancer_cluster_1 Farmer_breast_cancer_cluster_2 Ginestier_breast_cancer_20Q13_amplication_DN Hedenfalk breast cancer BRCAI vs BRCA2 Hedenfalk_breast_cancer_hereditary_vs_sporadic Landis_breast_cancer_progression_UP Landis ERBB2 breast prenoplastic UP Naderi_breast_cance_prognosis_UP Poola_invasive_breast_caner_UP

Pujana breast cancer lit int network Pujana_breast_cancer_with_BRCA1_mutated_UP SMID_breast_cancer_relapse_in_pleura_DN Sotiriou breast cancer_1_vs 3 UP Vantveer_breast_cancer_BRCAI_UP Vantveer_breast_Cancer_ESR1_DN Vantveer breast cancer metastasis DN Yang_breast_cancer_ESRI_bulk_DN Zhang_breast_cancer_progenitors_UP

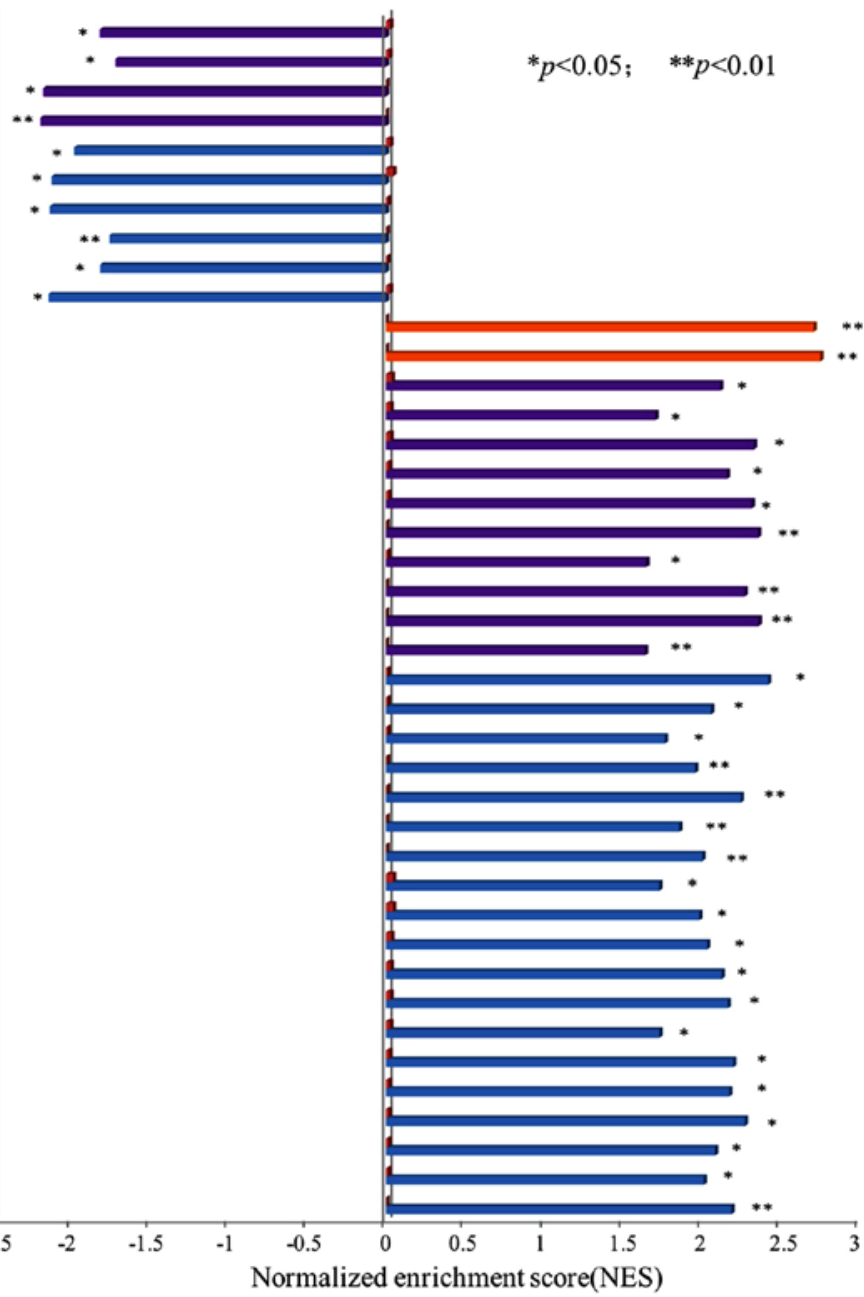

B

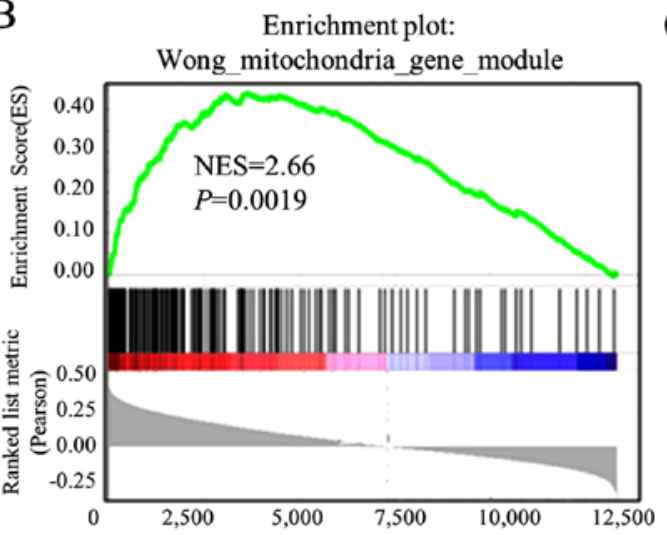

$\mathrm{C}$

Enrichment lot:
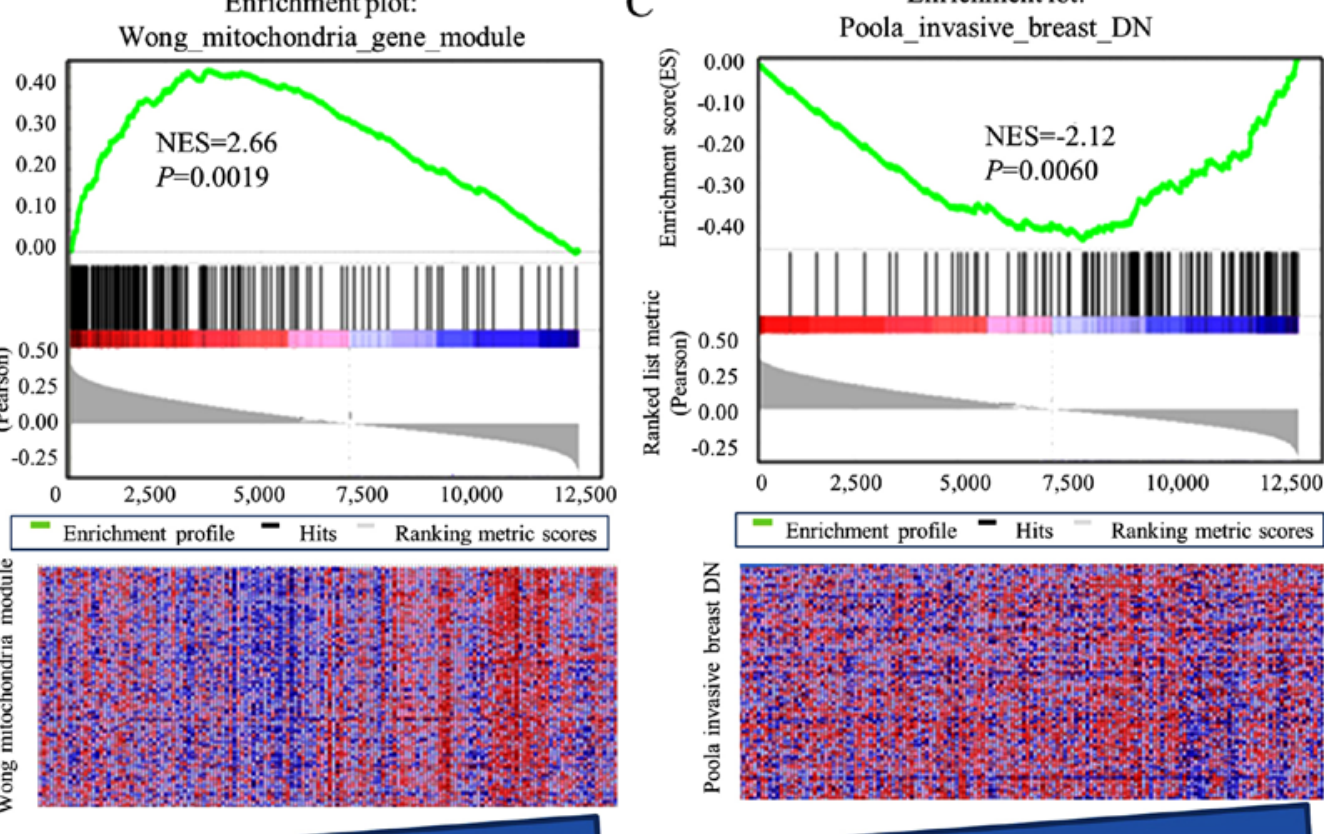

SHMT2 expression levels

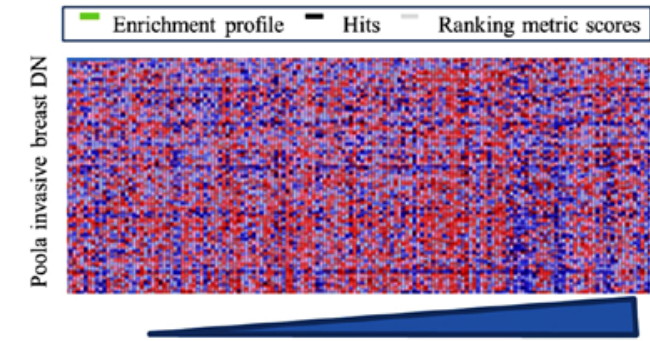

SHMT2 expression levels

Figure 1. Enrichment gene set analysis for $S H M T 2 \mathrm{mRNA}$ expression and gene signatures in breast cancers. The normalized enrichment score (ES) represents the strength of the relationship between phenotype and gene signature. The statistical significance of each signature is labeled at the side of the bar $(* \mathrm{p}<0.05$, ** $\mathrm{p}<0.01$ ). Detailed information about this computational method can be obtained from ref. 30 . The heat maps indicate the correlation between phenotype and expression levels of each signature gene. Columns are individual samples, and rows represent each gene. Each cell in the matrix represents the expression level of a gene in an individual sample. Red indicates a high level of expression, and green indicates a low level of expression; blue bars are invasive breast cancer signatures; purple bars are gene signatures associated with metastasis; yellow bars are mitochondria signature modules. (A) GESA analysis of SHMT2-high breast cancer. (B) GSEA results of the Wong mitochondria module. (C) Analysis results of Poola invasive breast cancer (downregulation) gene signature. 


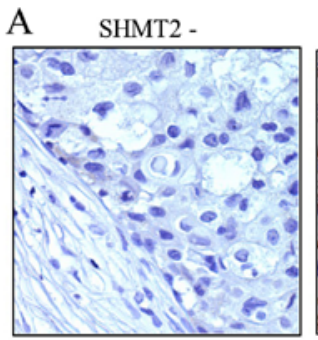

SHMT2 +

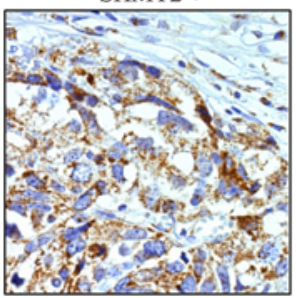

B ZJU set
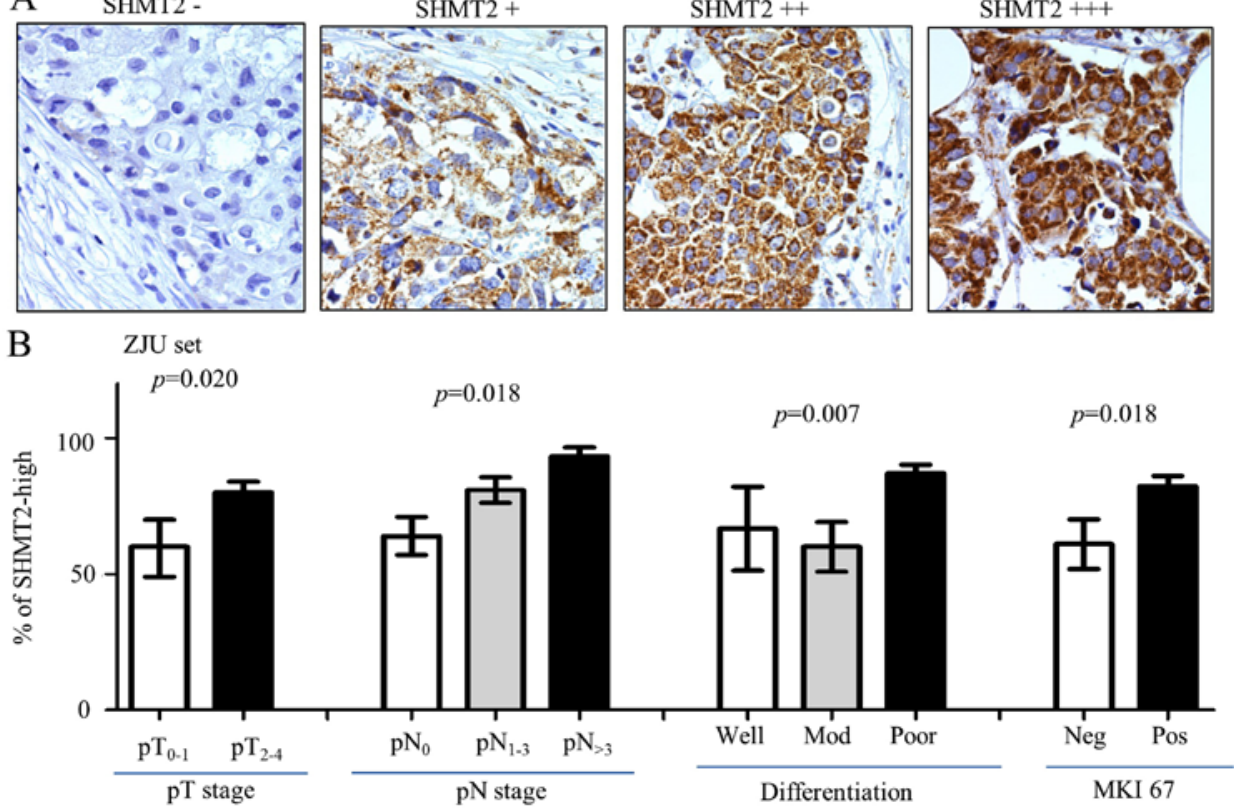

C NKI set $\quad p=0.014$

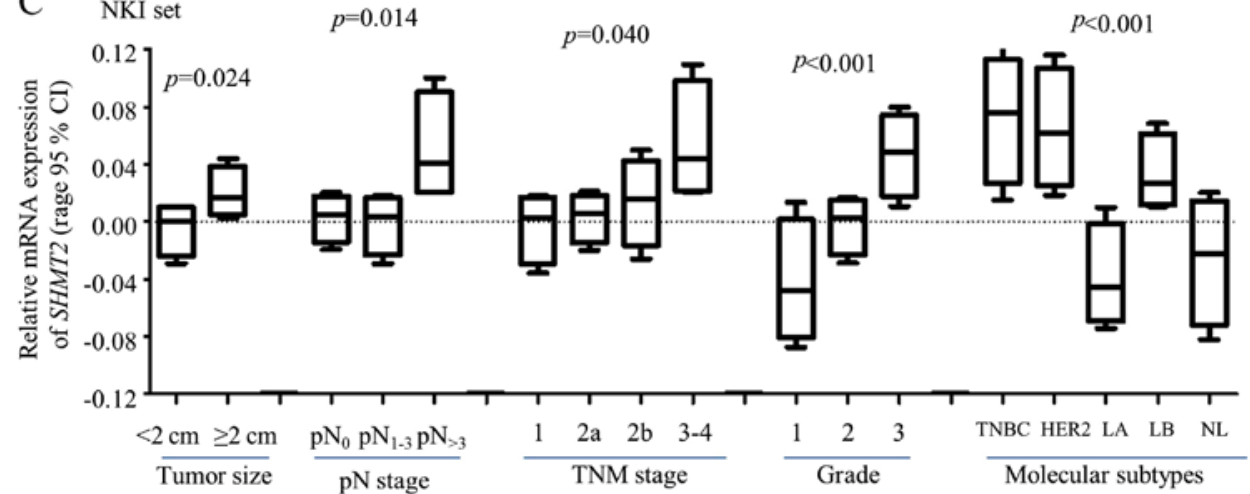

Figure 2. Clinical relevance of SHMT2 in breast cancer. Protein expression levels of SHMT2 and other biomarkers were determined using immunohistochemistry (IHC) staining. (A) Representative IHC images stained with SHMT2 (magnification, x200). (B) SHMT2 protein expression levels associated with pathological tumor and lymph node stage (pT and pN stages), poor differentiation and MKI-67 in ZJU set. Here, pT is pathological tumor stage; and the number represent tumor stage. $\mathrm{pN}$ is pathological lymph node stage; the number indicates how many lymph nodes involved. $\mathrm{pN}>3$ is $>3$ lymph nodes were involved. Mod, moderate differentiation; Neg, negative; Pos, positive. (C) ANOVA analysis result for SHMT2 mRNA expression levels and tumor size, pN and TNM stages, Elson grade, and intrinsic molecular subtypes of breast cancer. TNBC, basal-like breast cancer; HER2, Her2-positive, LA, luminal A; LB, luminal B; $\mathrm{NL}$, normal breast-like. The p-values represent overall ANOVA analysis results.

the HER2(+), subtype cases (Table I). The overall IHC results were consistent with the results yielded from NKI set (miRNA expression data) (Fig. 2C). The ANOVA results indicated that the SHMT2 mRNA expression level was significantly related to $\mathrm{pT}, \mathrm{pN}$ and TNM stages, and Elson grade. It is also higher in the TNBC, Her2-positive and luminal B subtype. Patients with these molecular subtypes had poor outcomes. Similar results were also revealed for the Ivshina, Desmedt, Pawitan and Wong datasets (data not shown). Overall, clinical relevance analysis validated GSEA results, which suggested that mitochondrial SHMT2 may be an indicator of breast cancer aggressiveness.

Prognostic validation of SHMT2. The prognostic significance of SHMT2 protein was also evaluated, based on the ZJU set. The Kaplan-Meier analysis of overall survival (OS) and progression-free survival (PFS) (Fig. 3A and B) revealed that high protein expression levels of SHMT2 negatively affected OS. The multivariate Cox proportional hazard analysis also indicated that high levels of SHMT2 protein were significantly and negatively associated with PFS in breast cancer patients. The HR for SHMT2 was 2.66 (95\% CI, 0.91-11.31), after adjusting for ER status, Elson histological stage and adjuvant chemotherapy (Fig. 3B). The HR for OS could not be calculated since no patient with SHMT2-low expression died from breast cancer.

The prognostic value of SHMT2 mRNA was validated using univariate and multivariate Cox analyses, based on five worldwide microarray datasets. We re-categorized SHMT2 scores into four subgroups $\left(\mathrm{Q}_{1}, \mathrm{Q}_{2}, \mathrm{Q}_{3}\right.$ and $\left.\mathrm{Q}_{4}\right)$ according to the mRNA expression levels of SHMT2. The lowest expression subgroup, $\mathrm{Q}_{1}$, was set as the baseline for calculation of the HRs.

OS and PFS analyses revealed that the mRNA expression levels of $S H M T 2$ were significantly associated with poor survival in a dose-dependent manner in the Pawitan, Wang, Ivshina and NKI sets, but not in the Desmedt set (Table III). We 
A

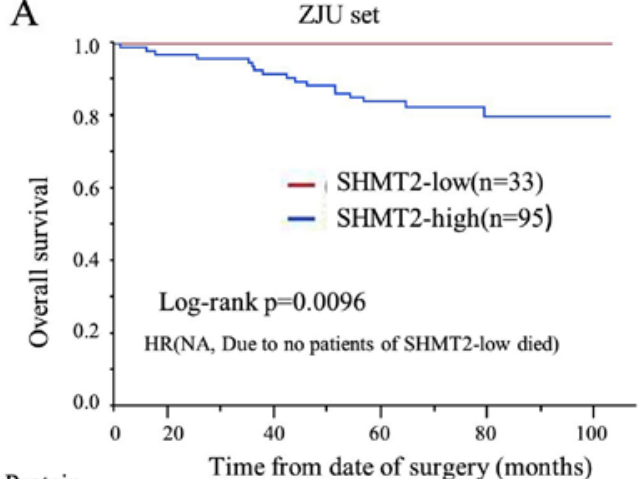

Protein

levels Patients at risk

$\begin{array}{lllllll}\text { Low } & 33 & 33 & 33 & 31 & 18 & 2 \\ \text { High } & 95 & 93 & 87 & 71 & 28 & 5\end{array}$

C NIKI set $(n=295)$

mRNA

$\begin{array}{lcccccc}\text { Q1 } & 73 & 73 & 71 & 70 & 47 & 35 \\ \text { Q2 - } & 74 & 72 & 64 & 43 & 42 & 32 \\ \text { Q3 - } & 72 & 70 & 64 & 58 & 41 & 30 \\ \text { Q4 } & 76 & 73 & 58 & 50 & 40 & 28\end{array}$

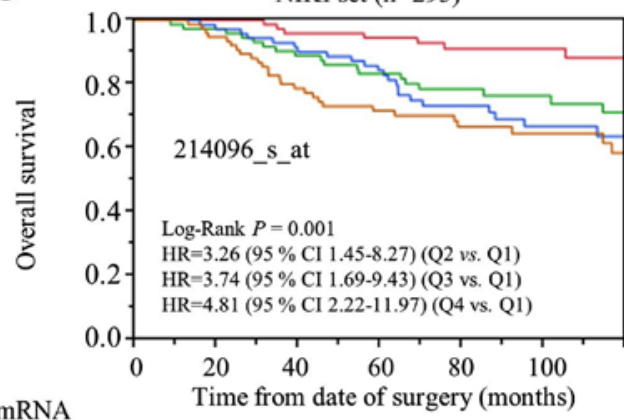

levels Patients at risk

B

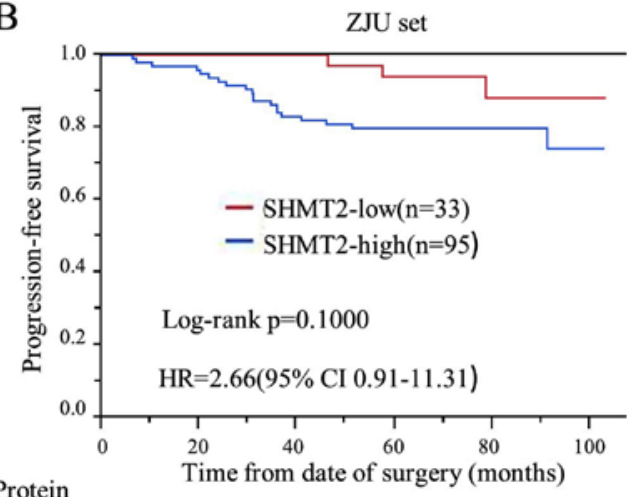

levels Patients at risk

$\begin{array}{lllllll}\text { Low } & 33 & 33 & 33 & 29 & 16 & 2 \\ \text { High } & 95 & 91 & 79 & 68 & 27 & 5\end{array}$

D

NIKI set $(\mathrm{n}=295)$

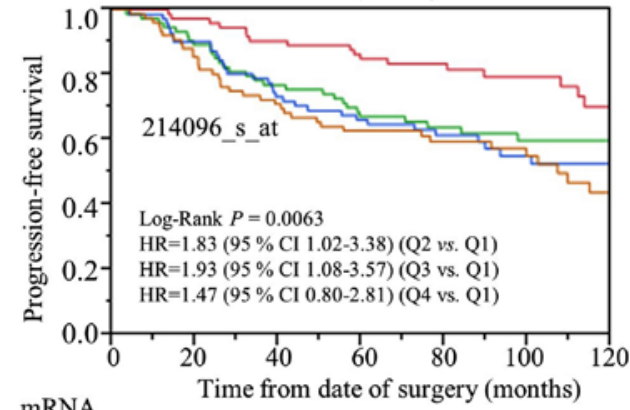

mRNA

levels Patients at risk

$\begin{array}{llllllll}\mathrm{Q} 1 \_ & 73 & 72 & 67 & 63 & 45 & 31 & 20\end{array}$

$\begin{array}{llllllll}\mathrm{Q} 2 & -74 & 67 & 57 & 49 & 37 & 27 & 22\end{array}$

$\begin{array}{llllllll}\mathrm{Q} 3 & 72 & 65 & 53 & 47 & 35 & 25 & 17\end{array}$

$\begin{array}{llllllll}\mathrm{Q} 4 & 76 & 66 & 53 & 45 & 36 & 24 & 14\end{array}$

E

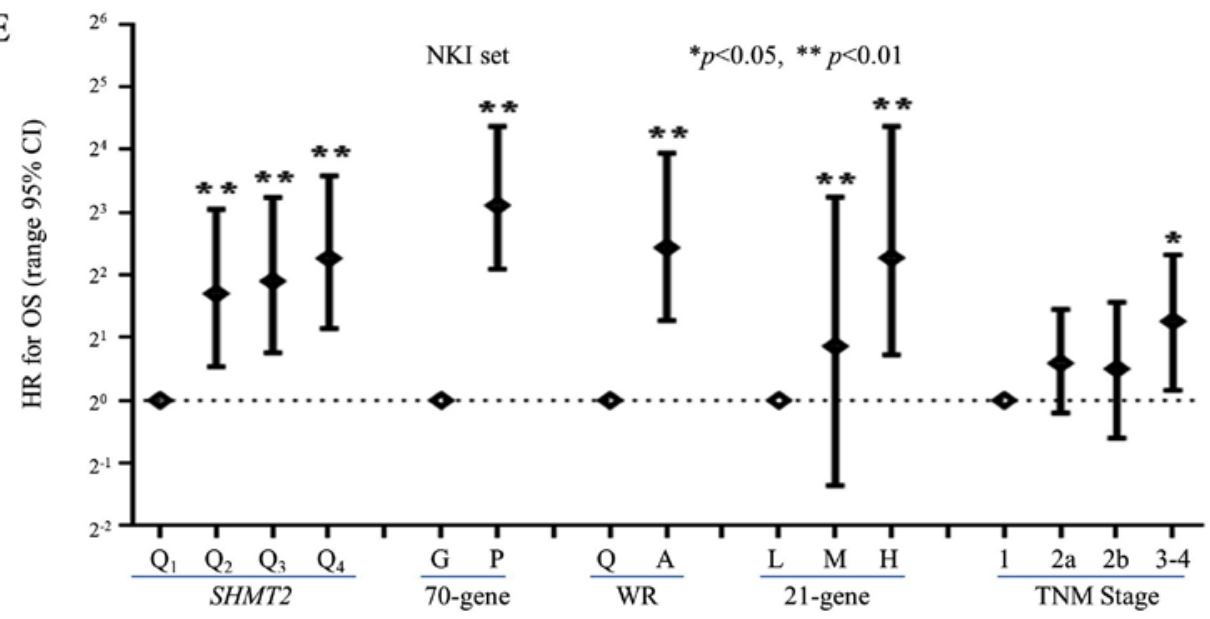

Figure 3. The prognostic significance and performance of SHMT2 in breast cancer patients. Kaplan-Meier analysis was performed to validate the prognostic significance of SHMT2. For protein levels of SHMT2 (ZJU set), the analysis was stratified as SHMT2-low (- and +) and SHMT2-high (++ and +++). For the mRNA levels of SHMT2 (NKI set), breast cancer patients were stratified into four subgroups based on their SHMT2 expression levels. $\mathrm{Q}_{0}$ was the 0 to the 25 th percentile; $\mathrm{Q}_{1}$ was the 25 th percentile to the median; $\mathrm{Q}_{2}$ was the median to the 75 th percentile; and $\mathrm{Q}_{3}$ was the 75 th percentile to the maximum. The $\mathrm{Q}_{0}, \mathrm{Q}_{1}, \mathrm{Q}_{2}$, and $\mathrm{Q}_{3}$ subgroups represent $S H M T 2$ mRNA levels, from low to high. The stratification method is described in Materials and methods. (A) The protein levels of SHMT2 and OS. (B) The protein levels of SHMT2 and PFS. (C) The mRNA levels of SHMT2 and OS. (D) The mRNA levels of SHMT2 and PFS. (E) The Cox analyses for $S H M T 2$, the 70 -gene signature, wound-response gene signature, 21 -gene recurrence score, and TNM stage, NKI set; ${ }^{*} \mathrm{p}<0.05$, ${ }^{* *} \mathrm{p}<0.01$.

found that there was a statistically significant trend between SHMT2 mRNA expression levels and the HRs for OS and PFS for all of the sets, except the Desmedt set. The pooled analysis results revealed that the adjusted HRs for PFS were 1.31 in $\mathrm{Q}_{2}$ (95\% CI, 0.91-1.89), 1.63 in $\mathrm{Q}_{3}(95 \% \mathrm{CI}, 1.15-2.34)$ and 1.75 in $\mathrm{Q}_{4}(95 \% \mathrm{CI}, 1.21-2.56)$. The Kaplan-Meier analysis further revealed that SHMT2 mRNA levels correlated with the PFS and OS of patients in NIKI sets (Fig. 3C and D). The Cox and Kaplan-Meier results also indicated that as SHMT2 mRNA levels increased the likelihood of a poor outcome increased. SHMT2 expression increased the probability of poor survival among breast cancer patients in a dose-dependent manner. 
Table III. Univariate and multivariate analyses for SHMT2 and survival microarray datasets.

\begin{tabular}{|c|c|c|c|c|}
\hline \multirow[b]{2}{*}{ Dataset } & \multicolumn{2}{|c|}{ Overall survival } & \multicolumn{2}{|c|}{ Progression-free survival } \\
\hline & $\begin{array}{c}\mathrm{HR} \\
(95 \% \mathrm{CI})\end{array}$ & $\begin{array}{l}\text { Adjusted HR } \\
(95 \% \mathrm{CI})^{\mathrm{a}}\end{array}$ & $\begin{array}{c}\mathrm{HR} \\
(95 \% \mathrm{CI})\end{array}$ & $\begin{array}{l}\text { Adjusted HR } \\
(95 \% \mathrm{CI})^{\mathrm{a}}\end{array}$ \\
\hline \multicolumn{5}{|c|}{ Desmedt } \\
\hline $\mathrm{Q}_{1}$ & Reference & Reference & Reference & Reference \\
\hline $\mathrm{Q}_{2}$ & $0.73(0.33-1.57)$ & $0.70(0.31-1.51)$ & $1.13(0.63-2.05)$ & $1.08(0.59-2.07)$ \\
\hline $\mathrm{Q}_{3}$ & $0.80(0.36-1.70)$ & $0.69(0.30-1.53)$ & $1.16(0.64-2.11)$ & $1.30(0.70-2.40)$ \\
\hline $\mathrm{Q}_{4}$ & $1.52(0.78-3.03)$ & $1.21(0.57-2.59)$ & $1.48(0.83-2.66)$ & $1.60(0.86-2.99)$ \\
\hline \multicolumn{5}{|l|}{ Pawitan } \\
\hline $\mathrm{Q}_{1}$ & Reference & Reference & Reference & Reference \\
\hline $\mathrm{Q}_{2}$ & $3.06(1.04-11.05)^{\mathrm{b}}$ & $2.51(0.81-9.32)$ & $3.79(1.16-16.94)^{\mathrm{b}}$ & $3.90(1.19-17.44)^{\mathrm{b}}$ \\
\hline $\mathrm{Q}_{3}$ & $2.82(0.94-10.31)$ & $2.07(0.64-7.88)$ & $3.06(0.88-13.96)$ & $2.25(0.61-10.56)$ \\
\hline $\mathrm{Q}_{4}$ & $4.38(1.58-15.36)^{\mathrm{c}}$ & $2.78(0.96-10.12)$ & $8.26(2.81-35.20)^{\mathrm{c}}$ & $5.29(1.73-23.03)^{c}$ \\
\hline \multicolumn{5}{|l|}{ Wang } \\
\hline $\mathrm{Q}_{1}$ & N/A & N/A & Reference & Reference \\
\hline $\mathrm{Q}_{2}$ & N/A & N/A & $1.27(0.73-2.22)$ & $1.28(0.74-2.24)$ \\
\hline $\mathrm{Q}_{3}$ & N/A & N/A & $0.91(0.51-1.62)$ & $0.93(0.52-1.67)$ \\
\hline $\mathrm{Q}_{4}$ & N/A & N/A & $1.81(1.08-3.09)^{\mathrm{b}}$ & $1.91(1.11-3.33)^{\mathrm{b}}$ \\
\hline \multicolumn{5}{|l|}{ Ivshina } \\
\hline $\mathrm{Q}_{1}$ & N/A & N/A & Reference & Reference \\
\hline $\mathrm{Q}_{2}$ & N/A & $\mathrm{N} / \mathrm{A}$ & $1.31(0.65-2.76)$ & $1.37(0.67-2.97)$ \\
\hline $\mathrm{Q}_{3}$ & N/A & N/A & $2.20(1.14-4.51)^{\mathrm{b}}$ & $2.11(1.07-4.46)^{\mathrm{b}}$ \\
\hline $\mathrm{Q}_{4}$ & N/A & N/A & $2.72(1.43-5.53)^{\mathrm{c}}$ & $2.49(1.23-5.38)^{\mathrm{b}}$ \\
\hline \multicolumn{5}{|l|}{ NKI } \\
\hline $\mathrm{Q}_{1}$ & Reference & Reference & Reference & Reference \\
\hline $\mathrm{Q}_{2}$ & $3.26(1.45-8.27)^{\mathrm{c}}$ & $3.18(1.42-8.07)^{\mathrm{c}}$ & $2.03(1.13-3.75)^{\mathrm{b}}$ & $2.04(1.14-3.77)^{\mathrm{b}}$ \\
\hline $\mathrm{Q}_{3}$ & $3.74(1.69-9.43)^{\mathrm{c}}$ & $2.75(1.21-7.04)^{\mathrm{b}}$ & $2.32(1.31-4.27)^{\mathrm{c}}$ & $1.91(1.06-3.58)^{\mathrm{b}}$ \\
\hline $\mathrm{Q}_{4}$ & $4.81(2.22-11.97)^{\mathrm{c}}$ & $2.79(1.24-7.11)^{\mathrm{c}}$ & $2.64(1.51-4.87)^{\mathrm{c}}$ & $1.94(1.07-3.63)^{\mathrm{b}}$ \\
\hline \multicolumn{5}{|l|}{ Pooled } \\
\hline $\mathrm{Q}_{1}$ & Reference & Reference & Reference & Reference \\
\hline $\mathrm{Q}_{2}$ & $1.71(1.07-2.80)^{\mathrm{b}}$ & $1.28(0.75-2.22)$ & $1.46(1.10-1.97)^{\mathrm{c}}$ & $1.31(0.91-1.89)$ \\
\hline $\mathrm{Q}_{3}$ & $1.85(1.15-3.02)^{\mathrm{b}}$ & $1.30(0.76-2.26)$ & $1.55(1.17-2.08)^{\mathrm{c}}$ & $1.63(1.15-2.34)^{\mathrm{c}}$ \\
\hline $\mathrm{Q}_{4}$ & $2.82(1.81-4.51)^{\mathrm{c}}$ & $1.47(0.86-2.56)$ & $2.26(1.72-3.00)^{\mathrm{c}}$ & $1.75(1.21-2.56)^{\mathrm{c}}$ \\
\hline
\end{tabular}

Univariate and multivariate analyses were conducted to evaluate HR of SHMT2. Here, $\mathrm{Q}_{1}, \mathrm{Q}_{2}, \mathrm{Q}_{3}$ and $\mathrm{Q}_{4}$ represent mRNA expression levels of SHMT2. The detail of grouping is described Materials and methods. ${ }^{a}$ For multivariate analysis, HR was adjusted by age, ER status, and Elston grade in the Desmedt set; HR was adjusted by age in the Ivshina datasets. In the Pawitan set, HR was adjusted by Elston grade, and ER and HER2 status. For the Wang set, HR was adjusted by ER status. The NKI set was adjusted by age and grade, ER, tumor size and lymph node status. HR was adjusted by age, ER status and Elston grade in the pool analysis. ${ }^{\mathrm{b}}$ Statistical significance, $\mathrm{p}<0.05$; ${ }^{\mathrm{c}} \mathrm{Statistical}$ significance, $\mathrm{p}<0.01$. SHMT2, serine hydroxylmethyltransferase $2 ; \mathrm{HR}$, proportional hazard ratio; $95 \% \mathrm{CI}, 95 \%$ confidence interval.

The prognostic performance of SHMT2 mRNA level was also compared with current prognostic gene signatures [70-genes (31), wound-response genes (16), the 21 gene recurrence score (17)] and TNM staging in the NKI dataset. The Cox analyses revealed that the HR was positively correlated with increased SHMT2 mRNA levels (Fig. 3E). The prognostic performance of SHMT2 was similar to the performance of the 70-genes, wound-response genes and the 21 gene recurrence score. Compared to TNM staging, both the SHMT2 mRNA levels and the gene signatures were more efficient prognostic indicators.
Prognostic performance of SHMT2 in the ER-positive vs. ER-negative subgroups. ER-negative breast cancers (e.g., HER2-positive and TNBC subtypes) have typically a poorer prognosis compared to ER-positive breast cancers (e.g., luminal A and B subtypes) (13). Currently, only a few biomarkers [e.g., uPA (17)] are available to predict the outcome and survival for ER-negative breast cancer patients. Our previous study revealed that ribonucleotide reductase small subunit M2 (RRM2) is a potential prognostic biomarker for ER-negative breast cancers (22). In the present study, we used 

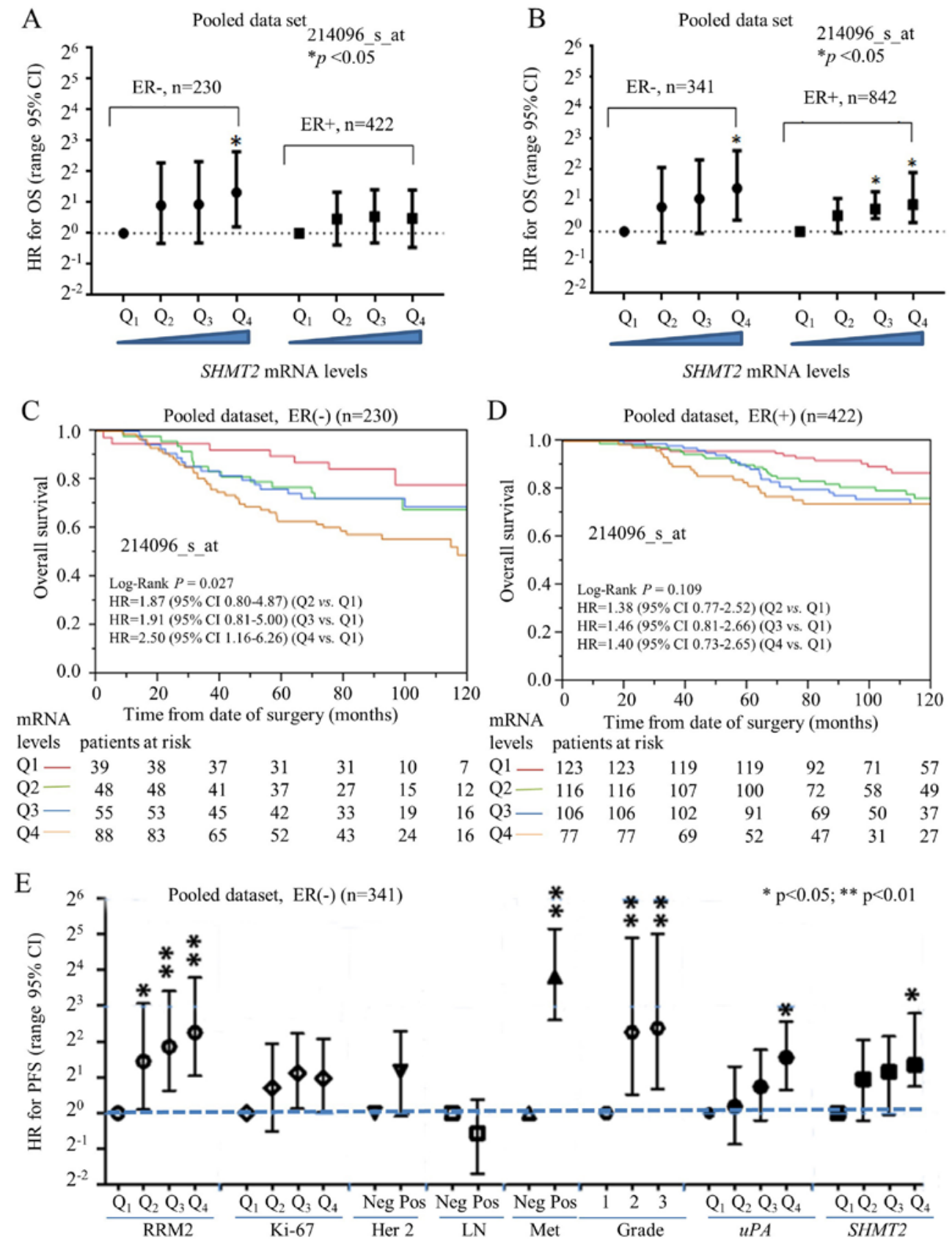

Figure 4. Stratification analysis for prognostic performance of SHMT2 in subgroups of ER-negative and ER-positive breast cancers. For the public breast cancer microarray data, we pooled all eligible breast cancers after normalization. (A) Cox proportional hazard analysis of SHMT2 for OS in ER-negative and ER-positive breast cancer. (B) Comparison of prognostic value of SHMT2 for PFS between ER-negative and ER-positive breast cancer. (C) Kaplan-Meier analysis was used to visualize the dose-dependent relationship between SHMT2 and the OS in ER-negative breast cancer. (D) mRNA levels of SHMT2 and OS in ER-positive breast cancer. (E) Comparing the prognostic performance of SHMT2 with other factors in ER-negative breast cancers. The HR of OS for various expression levels of SHMT2, HER2, lymph node involvement, distant metastasis, Elson grade, uPA and RRM2 were determined using Cox proportional hazard analysis. LN, lymph node; Met, metastasis; ${ }^{*} \mathrm{p}<0.05,{ }^{* *} \mathrm{p}<0.01$.

a stratified approach to compare the prognostic performance of SHMT2 in ER-positive vs. ER-negative breast cancer subtypes. Multivariate Cox analysis indicated that the HR value for OS steadily increased and significantly as levels of SHMT2 increased in the ER-negative subgroup (Fig. 4A). For PFS, however, SHMT2 was predictive for poor survival in both the ER-negative and ER-positive cancers (Fig. 4B). Kaplan-Meier analysis revealed SHMT2 had better prognostic value in the ER-positive and ER-negative subgroups. The results of the OS analysis indicated that SHMT2 significantly affected the survival of patients in the ER-negative (log-rank $\mathrm{p}=0.027$ ) (Fig. 4C), but not in the ER-positive (log-rank $\mathrm{p}=0.109$ ), breast cancer subgroups (Fig. 4D). Therefore, the overall prognostic performance of SHMT2 was better in the patients with ER-negative breast cancer.

The prognostic value of $S H M T 2$ in ER-negative breast cancer patients was further compared with other markers (e.g., HER-2 status, lymph node involvement, distant organ metastasis, Elson histological stage, RRM2 and uPA). The analysis of the pooled dataset revealed that the HR for SHMT2 
A

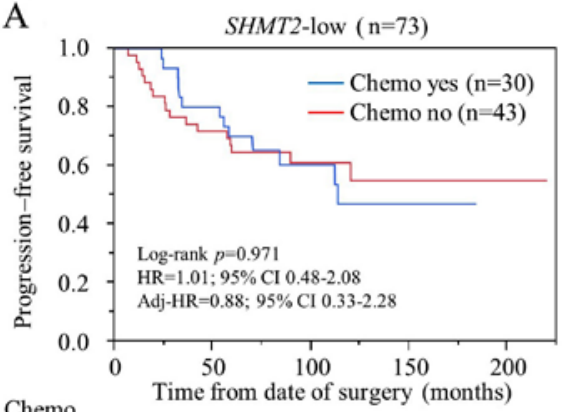

Chemo Time from

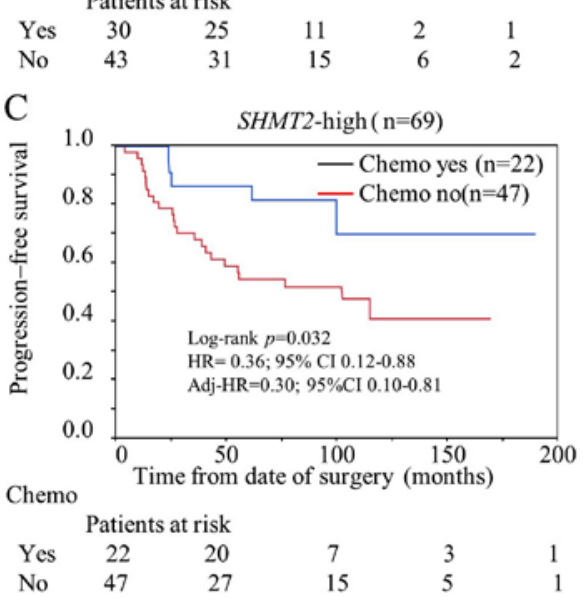

B

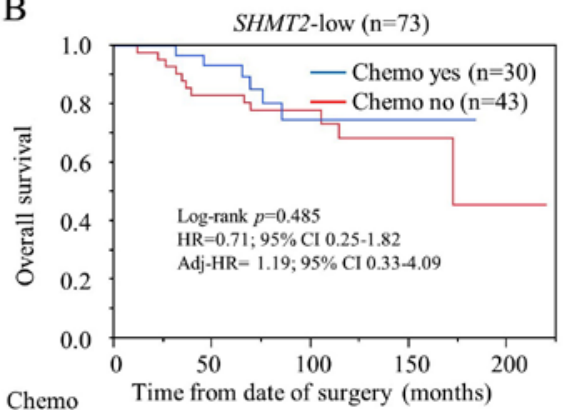

Chemo

\begin{tabular}{cccccc}
\multicolumn{7}{c}{ Patients at risk } \\
Yes & 30 & 29 & 12 & 3 & 1 \\
No & 43 & 35 & 19 & 7 & 2
\end{tabular}

$\mathrm{D}$

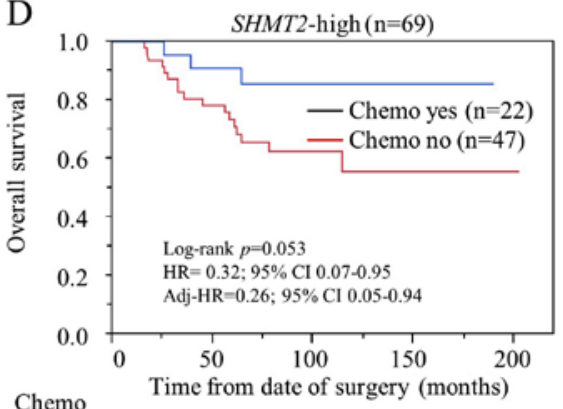

Chemo

\begin{tabular}{lccccc} 
Yes & 22 & 21 & 8 & 3 & 1 \\
\hline & 47 & 35 & 16 & 6 & 2
\end{tabular}

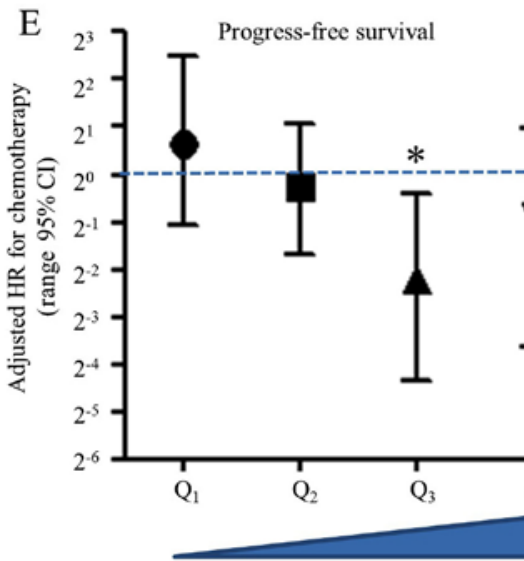

SHMT2 mRNA levels

SHMT2 mRNA levels

Figure 5. Stratification analysis for efficiency of chemotherapy in stage IIa breast cancer with different expression of SHMT2. In the Kaplan-Meier analysis, all participants in the NKI set were re-stratified as SHMT2-low $\left(\mathrm{Q}_{1}\right.$ and $\left.\mathrm{Q}_{2}\right)$ or SHMT2-high $\left(\mathrm{Q}_{3}\right.$ and $\left.\mathrm{Q}_{4}\right)$ subgroups. The HR represents the relative risk of chemotherapy (yes vs. no). Adj-HR is adjusted HR, the value of HR was adjusted by co-factors including age, hormone therapy, Elson grade and intrinsic molecular subtype. (A) Kaplan-Meier analysis of PFS for chemotherapy on SHMT2-low stage IIa breast cancer subgroup. (B) OS analysis for chemotherapy SHMT2-low stage IIa breast cancer subgroup. (C) PFS analysis for chemotherapy SHMT2-high stage IIa breast cancer subgroup. (D) OS analysis for chemotherapy SHMT2-high stage IIa breast cancer subgroup. (E) Multivariate Cox proportional hazard analysis for chemotherapy at different expression levels of SHMT2 subgroups.

steadily increased with increased SHMT2 mRNA expression levels for OS (data not shown) and for PFS (Fig. 4E). The prognostic performance of $S H M T 2$ was comparable to UPA and was better than Ki-67, HER-2 and lymph node involvement. However, SHMT2 was less efficient than RRM2 and distant metastasis.

Predictive capability of SHMT2 for chemotherapy selection in stage IIa breast cancer. Since SHMT2 has a genetic role in cancer development, we were also interested in exploring its potential role as a predictive biomarker for chemotherapy selection. We performed a stratified analysis to compare chemotherapy efficacy between the SHMT2-low and SHMT2-high breast cancer patients. The NKI set was used for the analysis since it was the only dataset with chemotherapy information. Only data from stage IIa patients were selected for analysis to avoid TNM staging-related confounding effects. Other potential confounding factors (hormone therapy, Elson grade and intrinsic molecular subtype) were also added to adjust the HR. Our results indicate that chemotherapy did not reduce the relative risk of OS and relapse in the SHMT2-low subgroup (Fig. 5A and B). 
However, chemotherapy did significantly reduce probability of relapse (adjusted $\mathrm{HR}=0.30 ; 95 \% \mathrm{CI}, 0.10-0.81$ ) and death (adjusted HR=0.26; 95\% CI, 0.05-0.94) in the SHMT2-high subgroups (Fig. 5C and D). Multivariate Cox analysis revealed that the relative risk of chemotherapy decreased significantly as SHMT2 mRNA expression increased (Fig. 5E). Overall, our findings suggest $S H M T 2$ may be a valid predictive biomarker for chemotherapy selection and efficacy.

\section{Discussion}

Combining multiple-tissue arrays with worldwide public microarray databases provides researchers the ability to discover novel biomarkers. The present study revealed that SHMT2 protein and mRNA levels were significantly associated with tumor grade, size, relapse, metastasis and positive lymph nodes (Table I and Fig. 2). The GSEA results provided further support for these findings (Fig. 1). We found that higher SHMT2 expression was significantly correlated with poor overall survival (OS) (log-rank $\mathrm{p}=0.0096)$, but not with progression-free survival (PFS) (Fig. 3A and B). This difference was due to the limited number of cases (128 cases) recorded in the ZJU set. Prognostic validation results indicated that SHMT2 overexpression was significantly associated with poor survival for breast cancer patients in a dose-dependent manner in four of five independent breast cancer microarray datasets. SHMT2 did not significantly affect the survival of breast cancer patients in the Desmedt set, most likely due to the small sample size of 158 cases. Nevertheless, our analysis of the Desmedt set indicated that there was an increasing trend in HR values as mRNA levels increased. We further assessed the prognostic performance of SHMT2 mRNA and compared it with multiple gene signatures, including 70 -genes, wound-response genes and the 21 gene recurrence score. Our findings suggested that SHMT2 not only correlated with poor prognosis in different breast cancer subgroups, but it also had prognostic power similar to several known multiple gene signatures.

Only a limited number of biomarkers are widely available for clinical application for ER-negative breast cancer patients. In view of the precision medicine era and current focus on outcome based therapy, it is likely that more breast cancer subtypes may be classified in the future. Identification of novel therapeutic targets and prognostic biomarkers may be critical for clinical and drug discovery purposes for breast cancer. Our findings suggest that SHMT2 levels were significantly associated with poor OS and PFS in patients with ER-negative and ER-positive breast cancer, but particularly in ER-negative cases (Fig. 4). In the ER-negative breast cancers, the prognostic value of SHMT2 proved greater than Ki-67, HER-2 and lymph node involvement, but poorer than RRM2 and distant metastasis (Fig. 4E). SHMT2 may be a valid prognostic biomarker for ER-negative breast cancer. The reasons why SHMT2 had greater prognostic efficiency in ER-negative breast cancer remain unknown. We seek to investigate the mechanisms involved in future studies.

Alterations in cellular metabolism have recently been recognized as a hallmark feature of cancer growth (32). Glycine metabolism is a key step in cancer cell proliferation. Study results also link the folate cycle to various enzymes that regulate
DNA synthesis and DNA methylation $(33,34)$. The folate cycle pathway may contribute to tumor homeostasis by providing essential precursors to sustain cancer cell growth and affect methylation capacities (35). SHMT2 has been implicated as a critical factor in serine/glycine metabolism in several cancer cell types, including breast cancer (36). This phenomenon ultimately affects patient mortality (37). Whether indeed, SHMT2 is a cancer driver gene, it may serve as a promising target for anticancer agents. Recent developments in our understanding of serine/glycine metabolic pathways provide novel translational opportunities for drug development, dietary intervention and biomarker discovery (38). Even though the SHMT2 localization in mitochondria makes it a difficult target for inhibition, we believe that further drug discovery efforts are warranted.

SHMT2 inhibitors are not commercially available for cancer therapy. However, agents such as methotrexate and fluorouracil, which inhibit downstream targets of SHMT2, are currently being used (38). These compounds have been used in combinations with other agents to treat breast cancer. Examples of these combinations include CMF (cytoxan, methotrexate and fluorouracil), FAC (fluorouracil, adriamycin and cytoxan) and CAF (cytoxan, adriamycin and fluorouracil). We performed a preliminary stratified analysis of stage IIa subgroup breast cancers (NKI set) and found that chemotherapy significantly reduced the relapse of breast cancer in SHMT2-high subgroup $(\mathrm{HR}=0.36$; 95\% 0.12-0.87), but not in SHMT2-low subgroup $(\mathrm{HR}=1.01 ; 95 \%$ 0.48-2.08), patients (Fig. 5). While reasons why SHMT2 had greater prognostic efficiency for ER-negative breast cancer compared to ER-positive breast cancer cases remain unknown, we intend to investigate the mechanisms involved in this difference in future studies.

We recognize that the small sample size of ZJU set was a limitation to the present study. We recommend further studies to validate our findings on prognostic value of SHMT2 in ER negative patients and chemotherapy selection. While GSEA analysis was performed in the present study, we did not perform laboratory experiments or animal studies to explore the exact mechanism of the SHMT2 effect on prognosis or chemotherapy response.

Taken together, our findings confirm the SHMT2 significance as a prognostic biomarker for breast cancer, particularly in ER-negative subgroup patients.

\section{Acknowledgements}

The present study was supported by the National Natural Science foundation of China (nos. 81171546 and 81301654), the Zhejiang Medical Research Platform for Important Programs (no. 2014ZDA018), the Committee of Hangzhou Science and Technology (no. 20140633B11), and the Foundation of Education Department of Zhejiang Province (no. Y201328265).

\section{References}

1. Anderson DD and Stover PJ: SHMT1 and SHMT2 are functionally redundant in nuclear de novo thymidylate biosynthesis. PLoS One 4: e5839, 2009.

2. Hebbring SJ, Chai Y, Ji Y, Abo RP, Jenkins GD, Fridley B, Zhang J, Eckloff BW, Wieben ED and Weinshilboum RM: Serine hydroxymethyltransferase 1 and 2: Gene sequence variation and functional genomic characterization. J Neurochem 120: 881-890, 2012. 
3. Kim SK, Jung WH and Koo JS: Differential expression of enzymes associated with serine/glycine metabolism in different breast cancer subtypes. PLoS One 9: e101004, 2014.

4. Lee GY, Haverty PM, Li L, Kljavin NM, Bourgon R, Lee J, Stern H, Modrusan Z, Seshagiri S, Zhang Z, et al: Comparative oncogenomics identifies PSMB4 and SHMT2 as potential cancer driver genes. Cancer Res 74: 3114-3126, 2014.

5. Wu XY and Lu L: Vitamin B6 deficiency, genome instability and cancer. Asian Pac J Cancer Prev 13: 5333-5338, 2012.

6. Leivonen SK, Rokka A, Ostling P, Kohonen P, Corthals GL, Kallioniemi O and Perälä M: Identification of miR-193b targets in breast cancer cells and systems biological analysis of their functional impact. Mol Cell Proteomics 10: M110.005322, 2011.

7. Antonov A, Agostini M, Morello M, Minieri M, Melino G and Amelio I: Bioinformatics analysis of the serine and glycine pathway in cancer cells. Oncotarget 5: 11004-11013, 2014

8. Ye J, Fan J, Venneti S, Wan YW, Pawel BR, Zhang J, Finley LW, Lu C, Lindsten T, Cross JR, et al: Serine catabolism regulates mitochondrial redox control during hypoxia. Cancer Discov 4: 1406-1417, 2014

9. Ma FJ, Liu ZB, Hu X, Ling H, Li S, Wu J and Shao ZM Prognostic value of myeloid differentiation primary response 88 and Toll-like receptor 4 in breast cancer patients. PLoS One 9 : e111639, 2014

10. Sørlie T, Wang Y, Xiao C, Johnsen H, Naume B, Samaha RR and Børresen-Dale AL: Distinct molecular mechanisms underlying clinically relevant subtypes of breast cancer: Gene expression analyses across three different platforms. BMC Genomics 7: 127, 2006.

11. Goldhirsch A, Wood WC, Coates AS, Gelber RD, Thürlimann B and Senn HJ; Panel members: Strategies for subtypes - dealing with the diversity of breast cancer: Highlights of the St. Gallen International Expert Consensus on the Primary Therapy of Early Breast Cancer 2011. Ann Oncol 22: 1736-1747, 2011

12. Reis-Filho JS and Tutt AN: Triple negative tumours: A critical review. Histopathology 52: 108-118, 2008.

13. Carey LA, Perou CM, Livasy CA, Dressler LG, Cowan D Conway K, Karaca G, Troester MA, Tse CK, Edmiston S, et al: Race, breast cancer subtypes, and survival in the Carolina Breast Cancer Study. JAMA 295: 2492-2502, 2006.

14. Martinez-Chacin RC, Keniry M and Dearth RK: Analysis of high fat diet induced genes during mammary gland development: Identifying role players in poor prognosis of breast cancer. BMC Res Notes 7: 543, 2014

15. Tobin NP, Harrell JC, Lövrot J, Egyhazi Brage S, FrostvikStolt M, Fernö M, Perou CM, Bergh J, Hatschek T and Lindström LS; TEX Trialists Group: The molecular subtype and tumor characteristics of breast cancer metastases significantly influence patient post-relapse survival. Ann Oncol: Oct 31, 2014 doi: 10.1093/annonc/mdu.

16. Saal LH, Johansson P, Holm K, Gruvberger-Saal SK, She QB, Maurer M, Koujak S, Ferrando AA, Malmström P, Memeo L, et al: Poor prognosis in carcinoma is associated with a gene expression signature of aberrant PTEN tumor suppressor pathway activity. Proc Natl Acad Sci USA 104: 7564-7569, 2007.

17. Paik S, Shak S, Tang G, Kim C, Baker J, Cronin M, Baehner FL, Walker MG, Watson D, Park T, et al: A multigene assay to predict recurrence of tamoxifen-treated, node-negative breast cancer. N Engl J Med 351: 2817-2826, 2004

18. Chang HY, Nuyten DS, Sneddon JB, Hastie T, Tibshirani R, Sørlie T, Dai H, He YD, van't Veer LJ, Bartelink H, et al: Robustness, scalability, and integration of a wound-response gene expression signature in predicting breast cancer survival. Proc Natl Acad Sci USA 102: 3738-3743, 2005

19. Staaf J,Ringnér M, Vallon-Christersson J,Jönsson G, BendahlPO, Holm K, Arason A, Gunnarsson H, Hegardt C, Agnarsson BA, et al: Identification of subtypes in human epidermal growth factor receptor 2 - positive breast cancer reveals a gene signature prognostic of outcome. J Clin Oncol 28: 1813-1820, 2010.

20. Teschendorff AE, Miremadi A, Pinder SE, Ellis IO and Caldas C An immune response gene expression module identifies a good prognosis subtype in estrogen receptor negative breast cancer. Genome Biol 8: R157, 2007.
21. Liu X, Zhang H, Lai L, Wang X, Loera S, Xue L, He H, Zhang K, Hu S, Huang Y, et al: Ribonucleotide reductase small subunit M2 serves as a prognostic biomarker and predicts poor survival of colorectal cancers. Clin Sci 124: 567-578, 2013

22. Zhang H, Liu X, Warden CD, Huang Y, Loera S, Xue L, Zhang S, Chu P, Zheng S and Yen Y: Prognostic and therapeutic significance of ribonucleotide reductase small subunit M2 in estrogen-negative breast cancers. BMC Cancer 14: 664, 2014

23. Harris L, Fritsche H, Mennel R, Norton L, Ravdin P, Taube S, Somerfield MR, Hayes DF and Bast RC Jr; American Society of Clinical Oncology: American Society of Clinical Oncology 2007 update of recommendations for the use of tumor markers in breast cancer. J Clin Oncol 25: 5287-5312, 2007.

24. Deyarmin B, Kane JL, Valente AL, van Laar R, Gallagher C, Shriver CD and Ellsworth RE: Effect of ASCO/CAP guidelines for determining ER status on molecular subtype. Ann Surg Oncol 20: 87-93, 2013.

25. Smeds J, Miller LD, Bjöhle J, Hall P, Klaar S, Liu ET, Pawitan Y, Ploner A and Bergh J: Gene profile and response to treatment. Ann Oncol 16 (Suppl 2): ii195-ii202, 2005.

26. Ivshina AV, George J, Senko O, Mow B, Putti TC, Smeds J, Lindahl T, Pawitan Y, Hall P, Nordgren H, et al: Genetic reclassification of histologic grade delineates new clinical subtypes of breast cancer. Cancer Res 66: 10292-10301, 2006.

27. Wang Y, Klijn JG, Zhang Y, Sieuwerts AM, Look MP, Yang F, Talantov D, Timmermans M, Meijer-van Gelder ME and $\mathrm{Yu} \mathrm{J}$ : Gene-expression profiles to predict distant metastasis of lymph-node-negative primary breast cancer. Lancet 365 : 671-679, 2005.

28. Desmedt C, Piette F, Loi S, Wang Y, Lallemand F, Haibe-Kains B, Viale G, Delorenzi M, Zhang Y, d'Assignies MS, et al: Strong time dependence of the 76-gene prognostic signature for nodenegative breast cancer patients in the TRANSBIG multicenter independent validation series. Clin Cancer Res 13: 3207-3214, 2007.

29. van de Vijver MJ, He YD, van't Veer LJ, Dai H, Hart AA, Voskuil DW, Schreiber GJ, Peterse JL, Roberts C, Marton MJ, et al: A gene-expression signature as a predictor of survival in breast cancer. N Engl J Med 347: 1999-2009, 2002.

30. Subramanian A, Tamayo P, Mootha VK, Mukherjee S, Ebert BL, Gillette MA, Paulovich A, Pomeroy SL, Golub TR, Lander ES, et al: Gene set enrichment analysis: A knowledge-based approach for interpreting genome-wide expression profiles. Proc Natl Acad Sci USA 102: 15545-15550, 2005.

31. van 't Veer LJ, Dai H, van de Vijver MJ, He YD, Hart AA, Mao M, Peterse HL, van der Kooy K, Marton MJ, Witteveen AT, et al: Gene expression profiling predicts clinical outcome of breast cancer. Nature 415: 530-536, 2002.

32. Hanahan D and Weinberg RA: Hallmarks of cancer: The next generation. Cell 144: 646-674, 2011.

33. Zwart SR, Jessup JM, Ji J and Smith SM: Saturation diving alters folate status and biomarkers of DNA damage and repair. PLoS One 7: e31058, 2012

34. Wang TC, Song YS, Wang H, Zhang J, Yu SF, Gu YE, Chen T, Wang Y, Shen HQ and Jia G: Oxidative DNA damage and global DNA hypomethylation are related to folate deficiency in chromate manufacturing workers. J Hazard Mater 213-214: 440-446, 2012.

35. Garrow TA, Brenner AA, Whitehead VM, Chen XN, Duncan RG, Korenberg JR and Shane B: Cloning of human cDNAs encoding mitochondrial and cytosolic serine hydroxymethyltransferases and chromosomal localization. J Biol Chem 268: 11910-11916, 1993.

36. Jain M, Nilsson R, Sharma S, Madhusudhan N, Kitami T, Souza AL, Kafri R, Kirschner MW, Clish CB and Mootha VK: Metabolite profiling identifies a key role for glycine in rapid cancer cell proliferation. Science 336: 1040-1044, 2012.

37. Paone A, Marani M, Fiascarelli A, Rinaldo S, Giardina G, Contestabile R, Paiardini A and Cutruzzolà F: SHMT1 knockdown induces apoptosis in lung cancer cells by causing uracil misincorporation. Cell Death Dis 5: e1525, 2014.

38. Amelio I, Cutruzzolá F, Antonov A, Agostini M and Melino G: Serine and glycine metabolism in cancer. Trends Biochem Sci 39: 191-198, 2014. 